\title{
French scientists turn to journals in English
}

\section{Declan Butler, Paris}

French researchers appear to be making the most of a 1994 court ruling allowing them to publish in languages other than French, according to a study by the Paris-based Observatoire des Sciences et des Techniques (OST). The study shows that French scientists are increasingly publishing in Englishlanguage journals.

The number of articles by French authors published in English-language journals has leapt between 1987 and 1997. The proportion of these published in the United States increased to more than a third, from 28.7 per cent to 39.1 per cent (see graph).

A similar pattern occurred in the proportion of articles appearing in journals published in Britain. In contrast, the number of French-authored articles appearing in journals published by Dutch publishing houses has remained flat, while French scientists have reduced their publications in German, Swiss and Japanese journals.

French scientists have always been ill at ease with the role of English as the international language of science. In 1994, a court intervention prevented the enactment of a law requiring nearly all publicly funded research to be published in French. The court

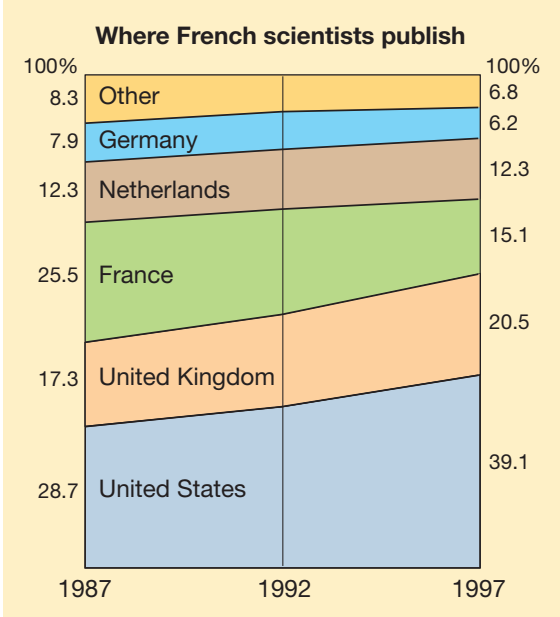

ruled that the law was contrary to the "freedom of communication and expression in teaching and research".

Reflecting this increased willingness (and desire) to publish abroad, the overall proportion of French-authored papers in French journals dropped by 41 per cent over the decade. This also reflects an increase in the number of scientists from overseas who publish in French journals. Japanese scientists, for example, doubled the number of their papers in French journals over the period, while British-authored papers have increased by around a third.

The data collected by the OST confirm a growing domination of the journals market by the United States, the United Kingdom and the Netherlands.

The European Union as a whole accounts for 1,810 of the 3,681 journals indexed by the Philadelphia-based Institute for Scientific Information, ahead of the United States, which produces 1,442 of the journals in the database. But within Europe, France is a minor publisher, with just 96 journals.

This compares with 776 published in the United Kingdom, 399 in the Netherlands a reflection of the role of large publishing houses such as Elsevier - and 288 in Germany (Japan produces 122). France's share of the world journal output fell from 3.1 per cent in 1987 to 2.6 per cent in 1997.

The OST points out that journals are just one of the many means of scientific communication, along with conferences, e-prints and electronic journals. Future studies, it emphasizes, will need to look beyond traditional journals to gain an accurate impression of publishing trends. 